\title{
Usability and Design Issues of Mobile Assisted Language Learning Application
}

\author{
Kashif Ishaq ${ }^{1}$, Fadhilah Rosdi ${ }^{2}$, Nor Azan Mat Zin ${ }^{3} *$, Adnan $\mathrm{Abid}^{4}$ \\ Faculty of Information Science and Technology, Universiti Kebangsaan Malaysia, Bangi, Malaysia ${ }^{1,2,3}$ \\ School of Systems and Technology (SST), University of Management and Technology, Lahore, Pakistan ${ }^{4}$
}

\begin{abstract}
This paper aims to look at teachers, government officials, and students for Literacy \& Numeracy Drive (LND), a smartphone app for students in Punjab province, Pakistan, to teach languages and math. Furthermore, to recognize LND usability and design problems while its use for grade three in schools. As the usability and design issues of LND were not discussed since the launch of this application. The methodology for this study is the questionnaire for teachers and semistructured interviews for government officials of District Sheikhupura and students. The result shows that LND has various usability and design problems in its current form, i.e., buttons, icons, color schemes, sluggish performance, and fonts. Besides, teachers, government officials, and students suggested that game-based learning consists of an interactive interface, phonics, key animations to be created and adopted. Highly engaging and appealing delivery of the curriculum and improvements in the appraisal will improve the participation of students and deliver better outcomes.
\end{abstract}

Keywords-Educational technology; language learning; literacy and numeracy drive; mobile application (App); m-learning; usability; user interface design

\section{INTRODUCTION}

Mobile learning (m-learning) technology involves the usage of mobile devices for instructional applications. Digital technology enhances the learning and students' success by providing the privilege of being able to study anywhere at all times, depending on the comfort of students [1]. The instructions should not be done at a fixed place or within the specified period such as a classroom [2]. M-learning seeks to bring colleges and organizations at the center of educational innovation and to fulfill user expectations for versatility and ubiquity [3]. However, one of the challenges confronted by mobile application (app) developers is that mobile devices present new barriers to usability that are difficult to model using conventional usability approaches. Usability standards and guidelines for desktop software used for designing mobile apps are not applicable and do not deal with problems associated with existing mobile devices constraints [4].

Two critical factors for the actual implementation of any information system are usability and user experience. Usability is the degree to which a single person may allow the usage of a program, invention, or service for the achievement of the objectives with quality, reliability and productivity in the form of a particular application [5]. The user experience is the observations and reactions of someone resulting from the use of software, device, or service or its expected use [6]. Usability is a critical issue in mobile apps, which can be avoided from being challenging to use by an adequately designed software, which is one of the main determinants of numerous apps' performance.

Usability testing of apps for portable devices is a new field of research that is confronted with several challenges due to the distinctive feature of small screen devices, restricted input capacity, and the evolving user perspective [7]. The usability testing of mobile learning systems is a critical mechanism for the functionality of mobile apps to ensure that mobile learning is easy, practical, and secure [8]. The technical deficiency and high rates of consumer satisfaction of mobile devices are important. Nevertheless, the use of virtual learning and evaluation in schooling advances slowly, owing to difficulties, such as digital technology, curricula, job growth, organization and management [9].

In comparison, issues including low efficiency, screensize, reduced bandwidth, poor display quality, storage space, availability of different file formats, lack of input features, usage of multiple modules, and operating systems for mobile devices are all at risk for the accessibility of M-learning applications. The indicators used for M-learning applications include learning power, effectiveness, modification, efficiency, coherence performance, quality, inaccuracy and satisfaction [10]. In compliance with the technology acceptance model (TAM) [11], if the approach is deemed user-friendly and practical, the consumer will adopt the knowledge structure as it is compatible with the intent to be used.

The techniques for developing functional mobile apps are not considered to be successful usability test methods. For this reason, the usability of mobile apps must be assessed through the development and implementation of appropriate usability testing methodologies. Nevertheless, to m-learning researchers and designers, this is a significant challenge along with usability and design issues. Therefore, this study aims to examine the usability and design issues of a mobile-assisted language learning application for public sector schools in Pakistan, named Literacy and Numeracy Drive (LND).

\section{A. Research Background}

1) Literacy and numeracy drive: Given the strengths of m-learning, the local government of Punjab has launched the LND, a mobile learning program for teaching and evaluation in public schools for grade three students (8-10 years old). The program was introduced in 2015 in 36 districts throughout the province of Punjab, where the conventional students'

*Corresponding Author 
assessment procedures such as the Punjab Examination Commission (PEC) are pricey, infrequent, and complex. The initiative comprises 52,394 schools; 403,172 teachers and 12,268,981 students [12] [13] [14] [15] [16].

The Department of School Education and the Punjab Information \& Technology Board, therefore, implemented a low-cost tablet-pc examination program for students to assess them during their monthly school visits by the Monitoring and Evaluation Assistant (MEA) (Fig. 1). The assessment software is linked to a massive question bank, with each question identifying the corresponding learning outcomes for students [14]. Currently, the Learning Outcomes (LOs) for English (Fig. 2), Urdu (Fig. 3) and Math's (Fig. 4) are measured for grade three students. The areas assessed are comprehension (Fig. 5), sentence completion, two and three-digit addition and subtraction, multiplication (Fig. 6) and division.

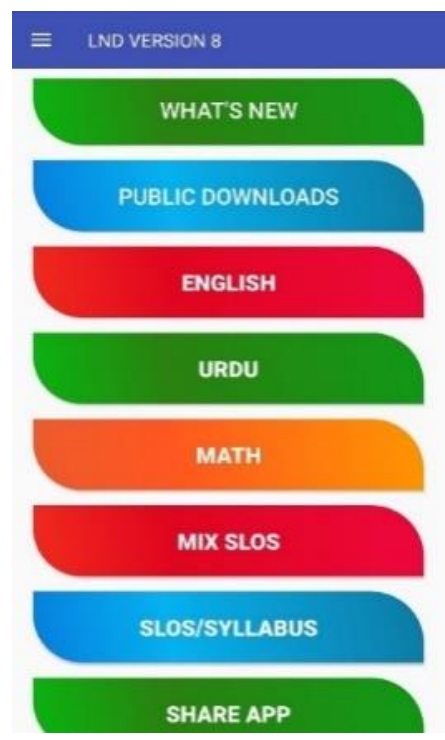

Fig. 1. LND Interface

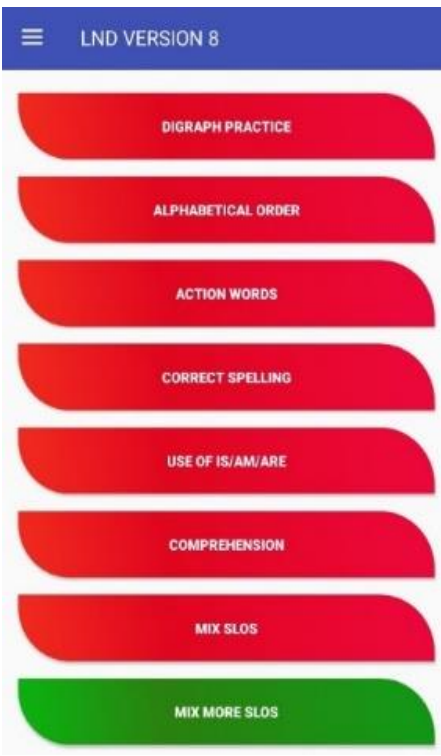

Fig. 2. Interface for English.

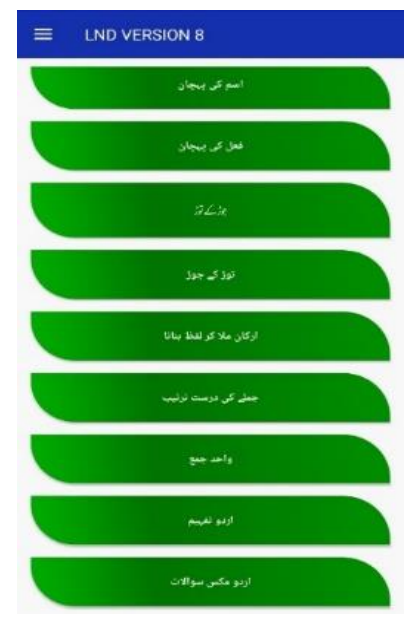

Fig. 3. Interface for Urdu.

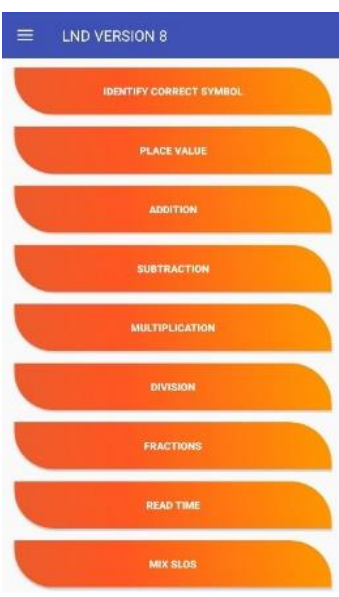

Fig. 4. Interface for Math.

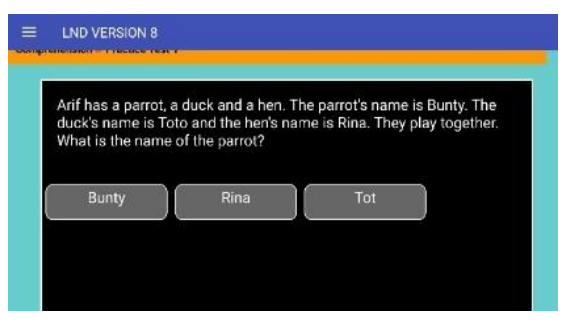

Fig. 5. LND English Test.

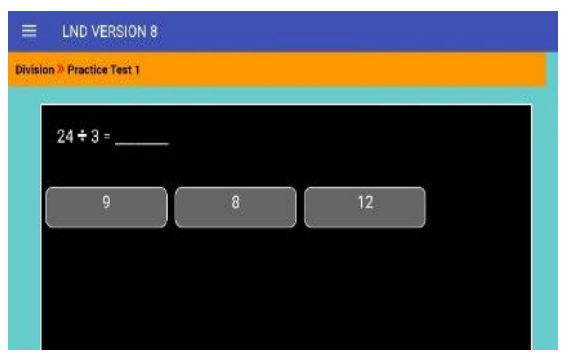

Fig. 6. LND Math Test.

The MEA, who also has an LND mobile app on his tablet, evaluates the students. An evaluation tablet allows questions to be periodically rendered from a central question-bank for each student, subject, and key LO, and multiple-choice 
questions are presented to the students (Fig. 5). A total of seven questions were tested with a student sample in a school. There are more than 47,000 public schools in Punjab, and the assessment cycle is accomplished in less than five minutes per student. The monthly evaluation is carried out with almost 329,000 participants and to date, nearly 6.7 million assessments have been completed by the MEAs (Fig. 7). The statistics of each evaluation is shared with training managers using the internet portal and full-term here SMS notifications [13] [14].

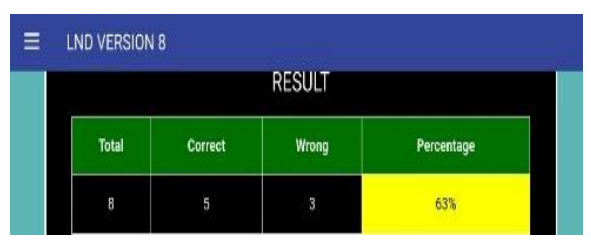

Fig. 7. LND Test Result.

\section{B. Motivation of this Research}

Although smartphone utilization is constantly popularized and increasing, users prefer to utilize mobile apps with advanced features for their study activities [17]. The LND implementation in government schools in Punjab Province is the focus of this research. This software has been downloaded and implemented in 52,394 [12] schools and used for teaching and evaluation, but no study has been done until now on its usability. Therefore, this study aims to determine the usability of the LND app. Evaluation of products and technologies is necessary [18]; thus, the usability evaluation for LND is carried out. Furthermore, since its implementation, there has been no usability evaluation carried out for the LND app. This evaluation is carried out among the stakeholders - teachers and administrators and students to gather feedback on the LND mobile app.

This paper is structured accordingly in which the related literature is summarized in Section 2. Section 3 presents the research method used. Section 4 summarized the results and discussion of the research, and finally, Section 5 concludes the paper with suggestions for improvements.

\section{LITERATURE REVIEW}

\section{A. Mobile Learning}

Mobile learning or m-learning is an extension of e-learning that enables consumers to learn with small and mobile wireless devices. Mobile apps are being created for online education in the educational world, which offers opportunities for students to learn whenever feasible, based on their convenience. Learning and teaching do not require a particular location or schedule but are versatile and can be performed anywhere at any time. M-learning has several distinct literature meanings, but all are restricted to learning from mobile devices and other hand-held technologies that are not time and location-based [19]. Mobile technology has continued to be used by academic organizations around the world because the relevance of using mobile technology to support teaching and learning is apparent and inevitable [20]. Smartphones have expanded instructional resources by reducing costs and increasing flexibility. To date, many efforts to introduce digital learning in institutions identify possible advantages and disadvantages of using these devices to allow access to learning such as (a) the potential of students to build self-centric pedagogy, (b) the ability to establish automated learning pedagogy, (c) the ability to promote useful communication tools for learning and support, and track the learners' knowledge [21] (d) the ability to provide flexibility in learning without the restriction of time and place, (e) to provide the ability to define the content according to the need either audio, video or presentation/images, and (f) to enhance the motivation for learning interactively [22].

2) Challenges for mobile learning: However, there are challenges for mobile learning students and teachers; mlearning (a) can separate technologically sound students from non-technically successful students, (b) can develop a sense of detachment among students and teachers, and (c) is hugely dependent on a networked resource [21]. Designers of mobile apps experience several challenges due to two leading causes, the usage context and device capacity:

a) Usage Context is the traditional usability methods apply to a standardized and well-established framework. In contrast, mobile learning environments are often volatile and hard to detect, forecast and simulate meaning. Users often employ different tools and use various application assessment methods.

b) Device capacity is a physical restriction of portable devices, particularly in narrow-screen size and resolution, which significantly impacts mobile apps' usability as it is visually uncomfortable to read human behavior and so from a small screen. Additionally, small icons and touchscreens minimize feedback and increase human mistakes because the usability performance depends mainly on the use of multipleinput and output processes. I think device capacity should include processing power too.

\section{B. Design and Issues of Mobile Educational Applications}

The user interface (UI) design concept for m-learning apps is one of the most significant mobile architecture dimensions comprising various functions such as ease of usage, customer retention, appeal, and learning abilities [23]. The design objective of a product is to increase consumer retention and engagement by the utility, ease of usage and pleasure in the experience. As it relies on enhancing consumers' awareness about what they are searching for, what they need and what they hear, effective design is thus critical for users to be significantly influenced by a product [24]. When designing the user interface, designers will take into account the form of users communicating with the program, the particular user requirements and device functionalities coupled with robustness, reduced error levels and excellent efficiency for a greater framework adoption. It will provide a well-built user experience to make sure the code is appropriately suited. Accuracy should be preserved across growing channels and apps. The Graphical User Interface (GUI), where user inputs are recognized by specific mobile device buttons or pointing methods that correspond to the screen, is the first form for the mobile user interface. The GUI presents important details on handheld app screens [10] [23]. 
Three user interface considerations need to be addressed when designing a mobile content; 1) Provide just a primary function. The mobile devices are tiny so, the specification should contain only the elements necessary for the task; the GUI may otherwise be frustrating for the users. 2) Have continuous association. Assignments should be built sequentially such that the consumer can only access a specific interface at a time. There is a significant distinction between a portable device and a computer user device. A function may be broken into a screening series if it needs many moves. 3) Limited on-screen assistance. Mobile users prefer to invest less time on the app than computer users. Therefore, GUI should be as simple as possible to complete the function while pursuing a transparent and rational flow. This element strongly refers to user experience, accuracy, minimum surprise concepts [25], and consistency [26]. Consistency is the key principle in design because usability and learnability enhance when similar components have consistent looks and functions in a similar way.

Older people usually face issues utilizing cell phones, including tiny keys and rubbery edges, limited text size displays, small keys, and letters. They are likely to hit the keyboard numbers inappropriately because they are not acquainted with slide or touch screen interface style plus dynamic menu configuration [27]. A major drawback is the screen size. Furthermore, small screen size causes visual problems, eye strain, or difficulty for visually impaired people.

Moreover, websites are not often optimized for smaller screens [28]. As a result, there are significant limitations on the size of the objects which can be viewed as well as the size of the font. A font size 12pt is probably too small and hard to read, even on a larger screen [29]. Besides, restricted space and memory and the ability for editing documents may also restrict mobile instructional practices [28]. The keys which are used must be wide enough and distinct from the rest of the interface component so that users can operate effectively. The common idea is that only graphical pictures can be used in the keys, and the text on them should also not be ambiguous and frustrating for children [29].

\section{Usability and Issues of Mobile Educational Applications}

Usability was introduced at the end of the 1980s [30] and is used regularly for the consistency and recognition of goods and services [31]. Nine standardized usability attributes have been established in current mobile usability studies, which are Learnability, Efficiency, Simplicity, Errors, Memorability, comprehensibility, user satisfaction, and learning output. Such usability attributes seek to measure the quality and usefulness of certain products [7]. Using these attributes, the present research aims to measure usability and identify design problems with the LND app currently used in schools [14]. Usability testing for mobile apps is an emerging field of research, as it has unique attributes, including touchscreen width, limited input area, and increasing user experiences, which is difficult to achieve [1] [7].

The small size of mobile devices can cause issues such as poor graphical appearance [32] and inadequate multimedia output [33]; poor display resolution [34], restricted input functions [35], keyboard limitations [36], restricted storage capacity [37], and low processing speed [38]. Other challenges that need to be addressed include difficulty reading on a smallscreen [39], failure in assignment completion [7], speed of Internet connectivity, evaluations on the smartphone, and students handling gadgets as toys from outside school [40].

A study by [8] found the dissatisfaction shared by students at the National University of Fiji for mobile learning apps in which thirty students participated. The results indicated significant usability issues and further improvement recommendations. Similarly, Primo, a discovery tools' usability study, was also administered on a medium-sized research tool for the library that detects user search behavioral patterns. The researchers investigated essential design concepts and functionality to grasp Primo's accessibility for users and carried out predictive usability tests which revealed that users encounter several technology challenges [41].

The effectiveness of mobile game-based learning needs positive smartphone learner behaviors, user experience, usability, design, and useful system [42]. Several mobile apps have been designed for use in technologically improved smartphones. Still, usability and design in almost all of the applications are not the main focus, whereas usability and design are the primary cause for those apps not being usable [43]. The smartphone LND app has been used in 52,000 schools since 2015 [14] but the English assessment [13] indicates its ineffective use because of poor design, low performance, font size problem, not suitable content and not being used by teachers [14]. Nonetheless, to date, no research has been conducted on the usability of this mobile app. Identifying usability and design issues is important to enhance the user experience of the LND mobile application, to achieve learning outcomes.

\section{Methodology}

\section{A. Setting and Participants}

The population of this study are primary school teachers and students of the Punjab province in Pakistan. There are 403,172 teachers (male and female) and 12,268,981 pupils (male and female).

The samples were randomly selected from 21 schools, out of the 1,247 in the Sheikhupura district. Fifty-seven (57) teachers who use LND applications in the classroom for teaching languages and Math subjects participated in the study. Besides, two government officials, the District Monitoring Officer (DMO) and the Assistant Commissioner (AC) and a total of 300 students also participated in the study. The teacher samples were self-administered questionnaire survey; thus, the returned rate obtained was 100 percent. The $\mathrm{DMO}$ and $\mathrm{AC}$ together with student participants, were interviewed using a semi-structured interview schedule. Students were interviewed instead of the given questionnaire because of the difficulty of reading and understanding the questionnaire items.

\section{B. Instrument}

1) Questionnaire: The questionnaire consists of 25 items (5 demographic and 20 usability items) adapted from [14]. The measured alpha Cronbach is 0.845 which indicates a high 
degree of internal uniformity. Items in the questionnaire cover demographic information, user experience, usability items (ease of use (5 items), accessibility ( 2 items), User Experience (10 items)). Demographic information includes age, class, education and school location. All items besides demographic use a 5-point Likert scale (1-Strongly disagree to 5-Strongly agree).

2) Interview schedule: A semi-structured interview schedule in Urdu which is the national language of Pakistan, was used. The interviews were conducted in Urdu because the participants are public office holders and also they felt comfortable using their mother tongue. Government officials were selected because they have been actively involved in public sector school educational activities in the district. They concurred with the need for the study and acknowledged that no one had investigated the smartphone LND app to date.

The interview schedule consists of demographic information for officers (age, employment, job experience) and (age only) for students in the first section and LND user experience, ease of use, and design issues are in the second section. LND specific issues are the context of the color scheme, font size, layout and design. Open-ended questions on the LND features that need enhancement to make it more effective, engaging, and beneficial for students were also included along with recommendations. The interview was carried for one hour with the DMO and $\mathrm{AC}$ in their respective offices.

The same instrument was used for students in the semistructured interview session, scheduled during the free class time and break time, where the researcher interviewed the students himself. This interview was also in Urdu because students are not able to speak English at the Primary level. The interview started with the demographic information of the participant, and then questions related to the LND application were asked. The questions about the usability and design issues were inquired along with suggestions for improvement.

\section{Data Analysis}

The Statistical Package for Social Science (SPSS 25.0) is used to evaluate teacher's questionnaire results, frequencies for demographic, Mean and Standard Deviation for the Usability and Design problem data. A qualitative method is used to analyze the interview results from students and the DMO and AC. Every interview was transcribed and then translated. The results were analyzed by identifying the answers from the interview, then coding and classifying them based on the theme. The results and analyses are translated into English, from the Urdu transcripts. Two language experts and corrections verified the translation of transcripts were made where required.

\section{RESULTS AND DisCUSSIONS}

There are $12(21.1 \%)$ males and $45(78.9 \%)$ females among the 57 teacher respondents. The age range of 18 (31.6\%) respondents are between 26-30 years old, whereas 9 $(15.8 \%)$ respondents are in the 31-35 age group while 13 $(22.8 \%)$ and $17(29.8 \%)$ respondents are in the 36-40 and above 40 age groups, respectively. As for students' participants, $138(46.0 \%)$ are males, and $162(54.0 \%)$ are females. The age range of 6 participants $(2.0 \%)$ was 5-7 years old, 217 (72.3 percent) participants are from 8-10 years old, 76 (25.3 percent) are 11-13 years old, whereas only one (0.3 percent) were older than 13 years. There were only two government officials, one male over 40 years of age and one female over 35 years.

\section{A. Survey Result}

The results from the teachers' survey are presented in Table I.

1) Usability issues of LND: Table I indicates that all items except items 8 and 9 have low mean scores (between 1.02 to 2.44 ), which translates to low usability. For any products such as smartphone apps, usability measure is important because a better usability score means an application is being used smoothly, efficiently and with satisfaction. Items 1 to 7 represent the usability issues encountered with the LND app. Respondents reported that it is difficult to find the icons and that the interface does not make the app easy to use, as indicated by items 1 (mean=2.44) and 2 (mean=2.25). Also, the respondents disagreed that the touch screen provides an easy input method as indicated by a very low item 3 score (mean=1.56). The difficulty of using the app is confirmed by respondents (item 8 mean=3.78) Assistance is important to guide a user in an application but items 4 (mean=2.14) and 5 (mean =1.45), indicate that there is little or assistance provided by the app. Additionally, there is no instruction to fix errors (item 6 mean $=1.15$ ) and there is no effort to improve user experience by the app provider (item 7 mean=1.02).

TABLE I. RESULTS OF LND APP USABILITY TEST

\begin{tabular}{|l|l|l|l|l|}
\hline Item No. & Items & $\mathbf{N}$ & $\mathbf{M}$ & SD \\
\hline 1 & The application icon is easy to find. & 57 & 2.44 & 1.09 \\
\hline 2 & The application interface is easy to use. & 57 & 2.25 & .61 \\
\hline 3 & $\begin{array}{l}\text { The application provides easy to use } \\
\text { touch screen input. }\end{array}$ & 57 & 1.56 & .50 \\
\hline 4 & $\begin{array}{l}\text { The application provides step by step } \\
\text { assistance to use it. }\end{array}$ & 57 & 2.14 & .72 \\
\hline 5 & $\begin{array}{l}\text { The application provides assistance in } \\
\text { difficulty. }\end{array}$ & 57 & 1.45 & .50 \\
\hline 6 & $\begin{array}{l}\text { The application instructs to fix the } \\
\text { problem automatically. }\end{array}$ & 57 & 1.15 & .37 \\
\hline 7 & $\begin{array}{l}\text { The application provider is taking steps } \\
\text { to improve the user experience of the } \\
\text { application. }\end{array}$ & 57 & 1.02 & .13 \\
\hline 8 & $\begin{array}{l}\text { The application is difficult to use. } \\
\text { The performance of the application is } \\
\text { slow. }\end{array}$ & 57 & 3.78 & .54 \\
\hline 9 & $\begin{array}{l}\text { The application makes me skillful in } \\
\text { learning English. }\end{array}$ & 57 & 1.84 & .65 \\
\hline 10 & $\begin{array}{l}\text { The use of application makes me } \\
\text { confident. }\end{array}$ & 57 & 1.21 & .41 \\
\hline 11 & \begin{tabular}{l} 
It helps me to enhance my vocabulary. \\
\hline 12
\end{tabular} & 57 & 1.54 & .57 \\
\hline
\end{tabular}

Note: Scale ranging from 1-Strongly Disagree to 5-Strongly Agree 
Furthermore, the performance of the LND app is slow during class usage (Item 9, mean=4.75). Moreover, items 10 (mean=1.84), $11(\mathrm{mean}=1.21)$ and $12(\mathrm{X}=1.54)$ show that respondents are not satisfied with the learning performance using the LND app.

Table II shows the results related to the design of the LND app.

2) Design issues of LND: In items 13 to 20 of Table II, the issues in the design of the LND are illustrated. The size of the font is a crucial element to consider for text reading on a mobile phone app, and it is challenging to use such an application if the font is not readable or difficult to read. Item 13 (mean=1.94) indicates that the majority of respondents face difficulty in reading text from the app screen. Navigation keys help users use the app easily and efficiently but the LND app lack this feature (Item 14 mean=1.14). Respondents very much disagreed that the icons are attractive and recognizable (Item 15 mean=1.70), or that the color scheme of buttons and application screen is attractive (Item 16 mean $=1.95$, and item 17 mean=1.56). The application's efficiency also has an impact on its usability because the user will not be able to learn quickly when the application operates poorly while carrying out the task. Voice instruction, simulations and instructional videos motivate people to learn quickly and effectively besides giving a clear demonstration of concepts realistically. However, this app has none of these multimedia elements as indicated by the lowest scores for items 18 to 20 $($ mean $=1.00)$.

Table III presents the results for LND app accessibility.

3) Accessibility of LND: According to Table III for LND accessibility, item $21(\overline{\text { mean }}=4.91$ ) shows that the app has a significant number of advertisements that create access and usage problems along with distraction from the learning process. Items 22 (mean=1.19) and 23 (mean=1.02) have the lowest mean scores, which indicate that the app does not provide self-recommendations for questions, and developers are not taking steps to improve the user experience of the application. Item $24(\overline{\text { Xmean }}=1.63)$ indicates that student does not get equal access to the app or equal time for practice during class (Item 25 mean=1.63) because every school is supplied with only one tablet for 30 students per class. Thus learning using the app hardly occurs since it requires proper attention and time to do practices as exercises.

In sum, usability testing of the LND app shows that it has low usability and accessibility besides many design problems, which also relate to app usability, as shown in Table IV.

Technology is important to enhance student success, dedication, and overall involvement in language learning. It provides students with unrestricted access to different services and methods to promote language acquisition in schools utilizing mobile apps [19]. Primary education is where the pupil needs extra support to learn languages in the classroom using a mobile application. If the mobile language learning application is convenient and simple to use, then the success of the students would also be good. However, results from this study demonstrate that there are usability, design, and accessibility issues of the LND app, which may not have contributed to students learning, as shown by their poor examination performance [36].

TABLE II. RESULTS FOR DESIGN ISSUES OF LND

\begin{tabular}{|l|l|l|l|l|}
\hline Item No. & Items & $\mathbf{N}$ & $\mathbf{M}$ & SD \\
\hline 13 & The font size is easy to read. & 57 & 1.94 & .44 \\
\hline 14 & $\begin{array}{l}\text { The application provides navigation } \\
\text { keys. }\end{array}$ & 57 & 1.14 & .35 \\
\hline 15 & $\begin{array}{l}\text { The icons and buttons are attractive and } \\
\text { recognizable. }\end{array}$ & 57 & 1.70 & .57 \\
\hline 16 & The color scheme of buttons is attractive. & 57 & 1.95 & .23 \\
\hline 17 & $\begin{array}{l}\text { The color scheme of the application } \\
\text { screen is attractive. }\end{array}$ & 57 & 1.56 & .50 \\
\hline 18 & $\begin{array}{l}\text { The application provides useful voice } \\
\text { instructions. }\end{array}$ & 57 & 1.00 & .00 \\
\hline 19 & $\begin{array}{l}\text { The application provides animations for } \\
\text { learning. }\end{array}$ & 57 & 1.00 & .00 \\
\hline 20 & $\begin{array}{l}\text { The application provides videos for } \\
\text { learning. }\end{array}$ & 57 & 1.00 & .00 \\
\hline
\end{tabular}

Note: Scale ranging from 1-Strongly Disagree to 5-Strongly Agree

TABLE III. RESULTS FOR ACCESSIBILITY OF LND APP

\begin{tabular}{|l|l|l|l|l|}
\hline Item No. & Items & N & M & SD \\
\hline 21 & $\begin{array}{l}\text { The application shows too many } \\
\text { advertisements. }\end{array}$ & 57 & 4.91 & .29 \\
\hline 22 & $\begin{array}{l}\text { The application provides a variety of } \\
\text { questions in its question bank. }\end{array}$ & 57 & 1.19 & .40 \\
\hline 23 & $\begin{array}{l}\text { The application provides self- } \\
\text { recommendations for questions. }\end{array}$ & 57 & 1.02 & .13 \\
\hline 24 & $\begin{array}{l}\text { Each student gets equal access to the } \\
\text { application in class. }\end{array}$ & 57 & 1.61 & .82 \\
\hline 25 & $\begin{array}{l}\text { Each student gets equal time for the } \\
\text { practice of the application in class. }\end{array}$ & 57 & 1.63 & .70 \\
\hline
\end{tabular}

Note: Scale ranging from 1-Strongly Disagree to 5-Strongly Agree

TABLE IV. OVERALl MEANS AND STANDARD DEVIATION FOR SUBSCALES

\begin{tabular}{|l|l|l|l|l|}
\hline Item No. & Subscales & N & Mean & Std. Deviation \\
\hline 1 & Usability & 57 & 2.095 & .218 \\
\hline 2 & Design Issues & 57 & 1.412 & .097 \\
\hline 3 & Accessibility & 57 & 2.073 & .317 \\
\hline
\end{tabular}

Note: Scale ranging from 1-Strongly Disagree to 5-Strongly Agree

\section{B. DMO, AC, and Students' Interview Results}

The analysis of interview from DMO, AC, and students is presented in Table V:

The interview results from DMO, AC, and students in Table V concur with teachers' survey findings. Usability test findings from the interview confirmed that the LND app has a complex structure, is not easy to use, has a problem in recognizing the icons and cannot build user confidence after using it. For the design issues, the font size used in the 
application creates a readability problem. Other issues like navigation keys, icons and buttons, buttons color scheme and screens demotivate users from using this application efficiently. Lastly, the content issue raised by DMO, AC, and students that content used in the application is different from the textbook, thus create issues for the students who still need to finish up the text-book based syllabus for the examination.

TABLE V. INTERVIEW RESULT

\begin{tabular}{|c|c|c|c|c|}
\hline Item no. & Category & Sub Category & DMO and AC's Response & Students' Response \\
\hline \multirow{7}{*}{1} & \multirow{7}{*}{ Usability } & Icons & $\begin{array}{l}\text { The icons in the application is difficult to } \\
\text { find. }\end{array}$ & $\begin{array}{l}\text { The icons and menu in the application is } \\
\text { difficult to recognize. }\end{array}$ \\
\hline & & Interface & $\begin{array}{l}\text { The interface of the application is } \\
\text { complex and not easy to scroll. }\end{array}$ & The interface is not easy to understand. \\
\hline & & Ease of use & $\begin{array}{l}\text { The application is not easy to use for } \\
\text { users. }\end{array}$ & The application is not easy to use. \\
\hline & & Assistance to use & $\begin{array}{l}\text { It does not provide any assistance for } \\
\text { using it. }\end{array}$ & $\begin{array}{l}\text { The application does not help or provide } \\
\text { assistance in complex tasks. }\end{array}$ \\
\hline & & Consistency & $\begin{array}{l}\text { There is too many inconsistencies in the } \\
\text { application. }\end{array}$ & $\begin{array}{l}\text { There is too much inconsistency in the } \\
\text { application. }\end{array}$ \\
\hline & & Confidence & $\begin{array}{l}\text { It cannot build confidence for the user } \\
\text { after using the application. }\end{array}$ & $\begin{array}{l}\text { The application is not building confidence } \\
\text { after using it. }\end{array}$ \\
\hline & & Complexity & The application is unnecessarily complex. & The structure of the application is complex. \\
\hline & \multirow{5}{*}{$\begin{array}{l}\text { Design (Colour } \\
\text { scheme, Icons, } \\
\text { and Interface) }\end{array}$} & Font Size & $\begin{array}{l}\text { The font size of the text is not suitable to } \\
\text { read. }\end{array}$ & $\begin{array}{l}\text { It is not easy to read the text in the } \\
\text { application }\end{array}$ \\
\hline & & Navigation Keys & $\begin{array}{l}\text { The application does not provide } \\
\text { navigation keys. }\end{array}$ & $\begin{array}{l}\text { The application does not provide navigation } \\
\text { keys. }\end{array}$ \\
\hline & & Icons and Buttons & $\begin{array}{l}\text { The icons and buttons are not attractive or } \\
\text { recognizable. }\end{array}$ & $\begin{array}{l}\text { The icons and buttons are not attractive to } \\
\text { recognize. }\end{array}$ \\
\hline & & $\begin{array}{l}\text { Colour Scheme (Buttons and } \\
\text { Screens) }\end{array}$ & $\begin{array}{l}\text { The color scheme of icons and buttons is } \\
\text { not attractive. }\end{array}$ & $\begin{array}{l}\text { The color scheme of icons and buttons is not } \\
\text { suitable. }\end{array}$ \\
\hline & & $\begin{array}{l}\text { Useful Features (Voice, Video, } \\
\text { Animation, and Translation) }\end{array}$ & $\begin{array}{l}\text { The application does not provide voice, } \\
\text { video, animations, and pronunciation for } \\
\text { learning. }\end{array}$ & $\begin{array}{l}\text { The application does not provide voice, } \\
\text { animations, and translation for learning } \\
\text { complex words. }\end{array}$ \\
\hline 3 & Other Issues & Content & $\begin{array}{l}\text { The content in the application is different } \\
\text { from the content of the textbook which } \\
\text { creates ambiguity for the students to } \\
\text { cover up the content in application and } \\
\text { textbook as well. }\end{array}$ & $\begin{array}{l}\text { The content in the application is different } \\
\text { from the textbooks which is the issue of } \\
\text { learning both syllabus at same time. }\end{array}$ \\
\hline 4 & $\begin{array}{l}\text { Overall } \\
\text { Comments }\end{array}$ & & $\begin{array}{l}\text { The outdated teaching and assessment } \\
\text { methods are not efficient, along with } \\
\text { LND mobile application. The application } \\
\text { is not rich enough in its current form and } \\
\text { also not useful in interactively helping } \\
\text { students. It is needed to develop a game- } \\
\text { based learning method to teach students } \\
\text { effectively. }\end{array}$ & $\begin{array}{l}\text { The current form of LND is not efficient, } \\
\text { which could help in learning efficiently and } \\
\text { smoothly. Fun based learning should be } \\
\text { adopted to overcome all the issues. }\end{array}$ \\
\hline
\end{tabular}




\section{CONCLUSION}

The purpose of the study was to investigate the usability and design issues from teachers, students, and government officers regarding the LND mobile app used in public schools of Punjab. The results of this study were based on the researchers' and practitioners' understanding of usability and design issues of the LND application. Based on the results, it was found that the interface was not easy to use; even the icon of the application was not easy to find. The majority of respondents were not interested to use the application due to poor interface design, small font size, unattractive color schemes, no assistance in difficulty and the app is noninteractive. Additionally, the content of the application was not consistent with the school syllabus, whereas students are supposed to learn using LND app alongside the teacher's classroom teaching using standard syllabus for their assessment promotion to the next level. Furthermore, feedback from the stakeholders has never been gathered to bring useful improvement to the app. The findings indicate that the application need to be redesigned by addressing all the identified issues and the content should be based on the syllabus of the target class level to achieve learning outcomes. The app should also be highly interactive, attractive by leveraging on visuals such as graphics, appropriate colour scheme and animation, that can be achieved by developing a digital game, as proposed by the respondents. Therefore, future research will involve design of a mobile game-based app following the current mobile design principles and guidelines so that the output will be usable and effective for users [44].

\section{ACKNOWLEDGMENT}

The authors would like to acknowledge UKM for the publication sponsorship under grant PP-FTSM-2020. They also acknowledged the efforts of School Education Department, Sheikhupura and Senior Headmistress of Government Girls High School, Kot Sondha, Sheikhupura, Punjab for helping to conduct this research.

\section{REFERENCES}

[1] Kumar and P. Mohite, "Usability of mobile learning applications: a systematic literature review," Journal of Computers in Education, vol. 5, no. 1, pp. 1-17, Dec. 2017.

[2] M. A. Chilton, "Technology in the Classroom: Using Video Links to Enable Long Distance Experiential Learning," Journal of Information Systems Education, vol. 23, no. 1, pp. 51-62, 2019.

[3] W.-L. Siu, T.-S. Lim, Y.-R. Chen, Y.-L. Chen, Y.-A. Jou, and Y.-C. Chen, "Using an English language education APP to understand the English level of students," 2018 27th Wireless and Optical Communication Conference (WOCC), pp. 1-3, Apr. 2018.

[4] J. Pettit and A. Kukulska-Hulme, "Going with the grain: Mobile devices in practice," Australasian Journal of Educational Technology, vol. 23, no. $1,2007$.

[5] ISO 9241-11:2018, "Ergonomics of human-system interaction - Part 11: Usability: Definitions and concepts". Retrieved from https://www.iso.org/obp/ui/\#iso:std:iso:9241:-11:ed-2:v1:en.

[6] ISO 9241-210:2010, "Ergonomics of human-system interaction - Part 210: Human-centred design for interactive systems". Retrieved from https://www.iso.org/obp/ui/\#iso:std:iso:9241:-210:ed-1:v1:en.

[7] R. Harrison, D. Flood, and D. Duce, "Usability of mobile applications: literature review and rationale for a new usability model," Journal of Interaction Science, vol. 1, no. 1, p. 1, 2013.
[8] B. A. Kumar and P. Mohite, "Usability guideline for mobile learning apps: an empirical study," International Journal of Mobile Learning and Organisation, vol. 10, no. 4, p. 223, 2016.

[9] S. A. Nikou and A. A. Economides, "A comparative study between a computer-based and a mobile-based assessment," Interactive Technology and Smart Education, vol. 16, no. 4, pp. 381-391, 2019.

[10] M. Sarrab, M. Elbasir, and S. Alnaeli, "Towards a quality model of technical aspects for mobile learning services: An empirical investigation," Computers in Human Behavior, vol. 55, pp. 100-112, 2016.

[11] F. D. Davis, "Perceived Usefulness, Perceived Ease of Use, and User Acceptance of Information Technology," MIS Quarterly, vol. 13, no. 3, p. 319, 1989.

[12] "PMIU," Real-time Monitoring and Student Learning Data Across Punjab. [Online]. Available: https://open.punjab.gov.pk/schools/home/ landing. [Accessed: 05-Jan-2020].

[13] K. Ishaq, N. A. M. Zin, F. Rosdi, A. Abid, and U. Farooq, "Effectiveness of Literacy \& Numeracy Drive (LND): A Students Perspective," 2019 International Conference on Innovative Computing (ICIC), 2019.

[14] K. Ishaq, N. Azan, F. Rosdi, A. Abid, and Q. Ali, "Usability of Mobile Assisted Language Learning App," International Journal of Advanced Computer Science and Applications, vol. 11, no. 1, 2020.

[15] K. Ishaq, N. Azan, F. Rosdi, A. Abid, and Q. Ali, "Usefulness of Mobile Assisted Language Learning in Primary Education," International Journal of Advanced Computer Science and Applications, vol. 11, no. 1, 2020.

[16] K. Ishaq, N. Azan, F. Rosdi, A. Abid, and Q. Ali, "Usefulness of Mobile Assisted Language Learning Application," International Journal of Engineering and Advanced Technology Regular Issue, vol. 9, no. 3, pp. 518-525, 2020.

[17] I. Arif, W. Aslam, and M. Ali, "Students' dependence on smartphones and its effect on purchasing behavior," South Asian Journal of Global Business Research, vol. 5, no. 2, pp. 285-302, 2016.

[18] K. Griggs, L. M. Bridges, and H. G. Rempel, "Library/mobile: tips on designing and developing mobile web sites," Code4lib journal, vol. 8.

[19] M. J. W. Lee and A. Chan, "Pervasive, lifestyle-integrated mobile learning for distance learners: an analysis and unexpected results from a podcasting study," Open Learning: The Journal of Open, Distance and eLearning, vol. 22, no. 3, pp. 201-218, Apr. 2007.

[20] I. M. I. Ezzelden, "MOBILE LEARNING FOR ENGLISH LANGUAGE LEARNING: BENEFITS AND CHALLENGES," European Journal of Open Education and E-learning Studies, vol. 4, no. 1, pp. 44-59, 2019.

[21] N. Yawasabere, "Benefits and Challenges of Mobile Learning Implementation: Story of Developing Nations," International Journal of Computer Applications, vol. 73, no. 1, pp. 23-27, 2013.

[22] A. Pandey, "Top 5 Benefits of Mobile Learning," EIDesign, 21-Mar2018. [Online]. Available: https://www.eidesign.net/top-5-benefitsmobile-learning/. [Accessed: 05-Jan-2020].

[23] A. Ali, M. Alrasheedi, A. Ouda, and L. F. Capretz, "A STUDY OF THE INTERFACE USABILITY ISSUES OF MOBILE LEARNING APPLICATIONS FOR SMART PHONES FROM THE USER'S PERSPECTIVE," International Journal on Integrating Technology in Education, vol. 3, no. 4, pp. 1-16, Dec. 2014.

[24] N. Ismail, F. Ahmad, N. Kamaruddin, and R. Ibrahim, "A review on usability issues in mobile applications," IOSR Journal of Mobile Computing \& Application, vol. 03, no. 03, pp. 47-52, 2016.

[25] R. P. Cortez and D. Roy, "Screen Interface Design for Mobile-assisted Language Learning in EFL Context: A Case Study in Japan,” Journal of Language Teaching and Research, vol. 3, no. 3, Jan. 2012.

[26] A. Nikolov, "Design principle: Consistency," Medium, 03-May-2017. [Online]. Available: https://uxdesign.cc/design-principle-consistency6b0cf7e7339f. [Accessed: 25-Mar-2020].

[27] C. Y. Wong, R. Ibrahim, T. A. Hamid, and E. I. Mansor, "Usability and Design Issues of Smartphone User Interface and Mobile Apps for Older Adults," Communications in Computer and Information Science User Science and Engineering, pp. 93-104, 2018. 
[28] H. Hashim, M. M. Yunus, M. A. Embi, and N. A. M. Ozir, "Mobileassisted Language Learning (MALL) for ESL Learners: A Review of Affordances and Constraints," Sains Humanika, vol. 9, no. 1-5, 2017.

[29] R. Kraleva, V. Kralev, and D. Kostadinova, "A Conceptual Design of Mobile Learning Applications for Preschool Children," International Journal of Computer Science and Information Security, vol. 14, no. 5, pp. 259-264, May 2016.

[30] K. A. Butler, "Usability engineering turns 10," interactions, vol. 3, no. 1, pp. 58-75, Feb. 1996.

[31] J. Dumas and J. Fox, "Usability Testing," Human Factors and Ergonomics Human-Computer Interaction, pp. 231-251, Feb. 2009.

[32] H.-J. Jung, "Fostering an English Teaching Environment: Factors Influencing English as a Foreign Language Teachers Adoption of Mobile Learning," Informatics In Education, vol. 14, no. 2, pp. 219-241, Jan. 2015.

[33] M. Park and T. Slater, "A Typology of Tasks for Mobile-Assisted Language Learning: Recommendations from a Small-Scale Needs Analysis," TESL Canada Journal, vol. 31, p. 93, 2015.

[34] T.-T. Wu, Y.-M. Huang, H.-C. Chao, and J. H. Park, "Personlized English reading sequencing based on learning portfolio analysis," Information Sciences, vol. 257, pp. 248-263, 2014.

[35] T. Kurisu, S. Matsumoto, T. Kashima, and M. Akiyoshi, "A study on constructing user adaptive learning environment to realize sustainable self-study," 2014 IEEE 7th International Workshop on Computational Intelligence and Applications (IWCIA), 2014.

[36] D. Bozdoğan, "MALL Revisited: Current Trends and Pedagogical Implications," Procedia - Social and Behavioral Sciences, vol. 195, pp. 932-939, 2015.

[37] J. Burston, "MALL: the pedagogical challenges," Computer Assisted Language Learning, vol. 27, no. 4, pp. 344-357, 2014.

[38] Y. Liu, H. Li, and C. Carlsson, "Factors driving the adoption of mlearning: An empirical study," Computers \& Education, vol. 55, no. 3, pp. 1211-1219, 2010.

[39] S.-C. Cheng, W.-Y. Hwang, D.-W. Wen, S.-Y. Wu, C.-H. Hsiehe, and C.-Y. Chen, "A Mobile and Web System with Contextual Familiarity and its Effect on Campus English Learning," 2010 Third IEEE International Conference on Digital Game and Intelligent Toy Enhanced Learning, pp. 222-224, Apr. 2010.

[40] L.-H. Wong and C.-K. Looi, "Mobile-Assisted Vocabulary Learning in Real-Life Setting for Primary School Students: Two Case Studies," 2010 6th IEEE International Conference on Wireless, Mobile, and Ubiquitous Technologies in Education, pp. 88-95, Apr. 2010.

[41] A. Nichols, A. Billey, P. Spitzform, A. Stokes, and C. Tran, "Kicking the Tires: A Usability Study of the Primo Discovery Tool," Journal of Web Librarianship, vol. 8, no. 2, pp. 172-195, Mar. 2014.

[42] R. Tahir and F. Arif, "Framework for Evaluating the Usability of Mobile Educational Applications for Children," Society of Digital Information and Wireless Communications, 2014.

[43] S. Shafiq, and A. T. Khan, "Role \& value of usability in educational learning via game based apps," International Journal of Scientific and Technology Research, vol. 7, no. 11, pp. 70-77, 2018.

[44] S. A. Alserri, N. A. M. Zin, and T. S. M. T. Wook, "Gender-based engagement model for designing serious games," 2017 6th International Conference on Electrical Engineering and Informatics (ICEEI), 2017.

\section{RESEARCH PROFILE}

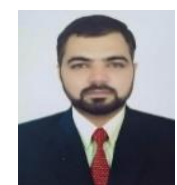

Kashif Ishaq is a Ph.D. scholar in Faculty of Information Science and Technology, Univers iti Kebangsaan Malaysia. He is working on his Ph.D. research title "Serious Game Design Model for Language Learning in Cultural Context". He received his Masters in Information Technology from Department of Computer Science, University of Management and Technology, Pakistan. His area of expertise are Serious Games, MALL, E-Learning, and Usability.

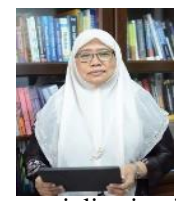

Nor Azan Mat Zin received the Ph.D. in 2005 and working as Professor in Research Centre for Software Technology and Management (SOFTAM), Faculty of Information Science and Technology, Universiti Kebangsaan Malaysia. She is $t$ he Head of Games lab, Multimedia Software and Usability Research Group and area of specialization is Serious games, HCI (Accessibility), E-learning Technology.

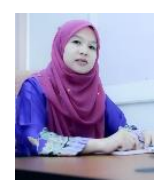

Fadhilah Rosdi received the Ph.D. from University of Malaya and working as Senior Lecturer in Research Centre for Software Technology and Management (SOFTAM), Faculty of Information Science and Technology, Universiti Kebangsaan Malaysia. Her area of specialization is Speech Processing Knowledge Based System.

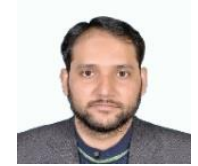

Adnan Abid was born in Gujranwala, Pakistan, in 1979. He received the B.S. degree from the National University of Computer and Emerging Science, Pakistan, in 2001, th e M.S. degree in information technology from the National University of Science and Technology, Pakistan, in 2007, and the Ph.D. degree in computer science from Politecnico Di Milano, Italy, in 2012. He is currently an Associate Professor with the Department of Computer Science, University of Management and Technology, Pakistan. His research interests include computer science education, MALL, information retrieval, and data management. He is a member of the IEEE Computer Society. 